\title{
Fifteen years on the road- Strange Matter continues its journey
}

\author{
www.strangematterexhibit.com
}

trange Matter started as an "overlooked
detail" of the Materials Research Society (MRS) Headquarters Task Force's mission to construct a new building in 1997. Alan Taub (University of Michigan), the task force chair, realized that everything for the building was complete, except for the lobby. Little thought had gone into the planning of this space, other than the fact that there needed to be a place where visitors could sit and wait.

Taub requested that fellow task force member Merrilea Mayo (Mayo Enterprises) think of a way to "finish" the lobby. So after a day of thought, she approached Taub with a proposal: Instead of merely decorating the lobby, as if it were a hotel space, could she instead create a small materials science museum with a team of volunteers?

The team hired Thomas Rockwell, a designer now affiliated with the Exploratorium in San Francisco, to develop the exhibit. He was the perfect genetic fit for the project - a descendent of well-known American painter Norman Rockwell on one side of his family and of a former director of engineering at the National Science Foundation (NSF) on the other side. Elizabeth Fleischer (MRS), Alan

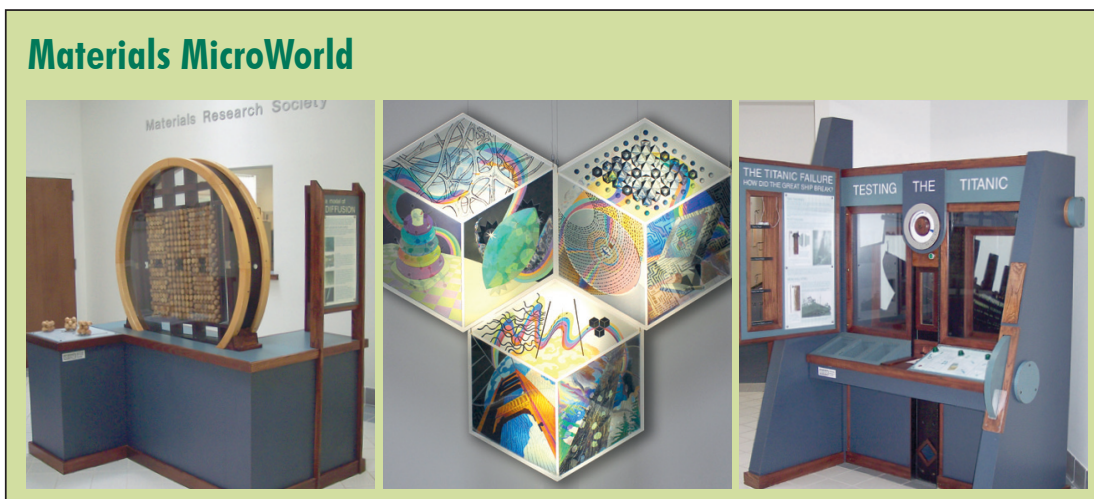

Original Materials Research Society headquarters lobby displays: (left) machine demonstrating diffusion, (middle) image-shifting artwork, and (right) toughness tester tied in with the Titanic failure.
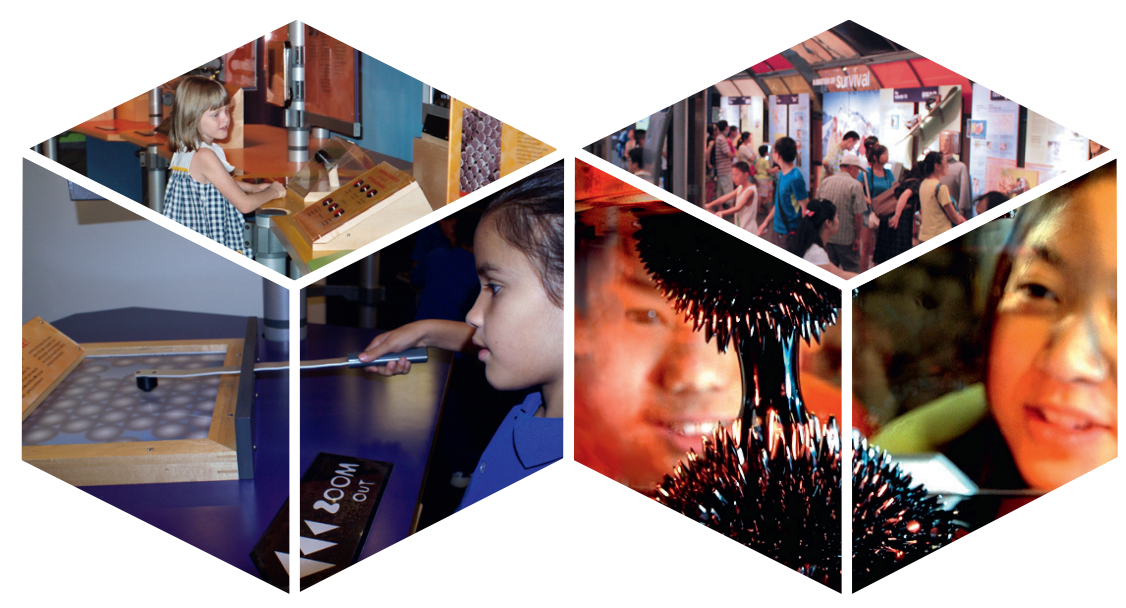

Hurd (Los Alamos National Laboratory), and Alex King (Ames Laboratory) substantially contributed to the group. In the end, there were four displays, including one on the Titanic's metallurgical failures (genuine artifacts borrowed from the National Institute of Standards and Technology metallurgists) and Austine Wood Comarow's materials-themed Polage art — a colorful wall hanging that used Saran Wrap's birefringent properties to create vivid, colored mosaic images from layers of this otherwise transparent material.

When the exhibit opened for the MRS Council (Board) meeting that year, it was an instant hit - so much so that Hurd exclaimed, "Hey, maybe we could do this for real, build a real museum exhibit!" This was the beginning of his and Shenda Baker's (Synedgen Inc.) quest to create a real exhibit, with the enthusiastic blessing of the Board. "I am constantly amazed that my "lemon" of an assignment to decorate the lobby turned into a lifetime supply of lemonade, with Strange Matter still going strong," said Mayo. "Sometimes the smallest most incidental tasks you take on become your most enduring legacy."

From this experience, MRS created the idea of a traveling exhibit featuring materials science to explain to the general public how materials play an active role in daily life. The purpose of the project was to present the basic principles, issues, and trends of materials research to the general public; develop new links with informal science education; interest students in materials science careers; and inform citizens about the pivotal importance and wide applicability of materials science research.

MRS hired Exhibition Manager, Richard A. Souza, and drafted and submitted a proposal to the NSF seeking support for the fledgling project titled Materials MicroWorld, which later became Strange Matter. MRS, along with NSF and the 
Ontario Science Centre (OSC), developed this traveling and interactive exhibit, receiving input from MRS scientists, distinguished members of related scientific communities, and experts and evaluators from museums and educational fields. Strange Matter opened to the public at the OSC in Toronto, Canada, on June 28, 2003.

In 2004, the American Association of Museums honored the Strange Matter website with the MUSE Award, recognizing its high standards of excellence in the use of media and technology for the interpretation of education in science. The site (www.strangematterexhibit. com) is still very active and includes online games, experiments, and videos for both teachers and families.

The exhibit has been to more than 55 science centers in seven countries and is scheduled through the end of 2018 . Approximately 50 hands-on experiences allow participants to observe and interact with crystals, magnetic liquids, amorphous metals, and foam. The exhibit, originally scheduled to be a three-year tour, is celebrating its 15 th year. It is the longest traveling exhibition created by the OSC.
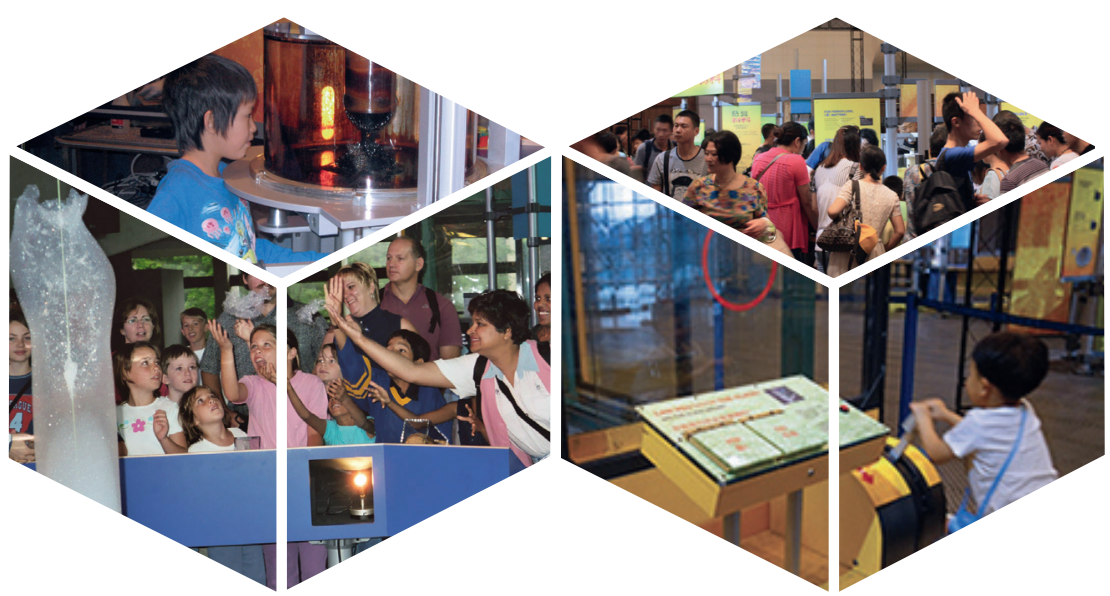

Over the years, the Strange Matter project led to an increase and proliferation of Broader Impact programming at MRS Meetings, so much so that the Public Outreach Committee submitted a white paper detailing the need to create a Broader Impact Program Development Subcommittee under the auspices of the Meetings Committee. The designed intention of the subcommittee is to provide for a systematic review and approval process for the submission of broader impact programs to the Meetings Committee.

\section{strange Excerpts from the journey}

We enjoyed hosting the Strange Matter exhibition in Boston. It was hugely popular with both the visitors and Museum staff. l'd place it in the top five of the traveling exhibits I've seen here in my twenty years.

Paul Fontaine, Associate Vice President, Visitor Programs Museum of Science, Boston

We were concerned about the subject of materials science: it could be very dull, and it might not be engaging for a diverse audience.

Your team addressed all these issues, and we are thrilled to have an exhibit that has real science!

Gail R. Becker, Executive Director Louisville Science Center

Our staff was very impressed with the number and variety of interactives available for visitors. Personally, I also believe it is one of the most engaging science exhibits I have seen.

Paul Spana, Exhibits Manager

Space Center Houston

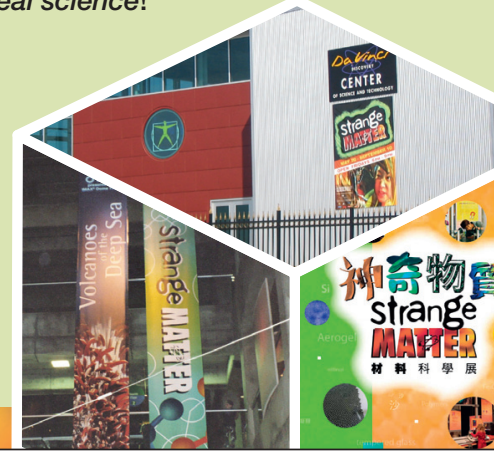

In 2005, a national community of researchers and informal science educators dedicated to fostering public awareness, engagement, and understanding of nanoscale science, engineering, and technology formed the Nanoscale Informal Science Education (NISE) Network. A 10-year, USD\$40 million NSF grant was awarded to carry out the network's objectives: to advance the field of informal learning by incorporating current nano-science into museum exhibits and programs; improving the practices and skills of educators and scientists; and creating lasting, valuable relationships among individuals and organizations. MRS was the only professional science society to join as a sub-awardee at the project's inception, along with 12 science center partners.

The relationship/partnership with science centers had been previously established through the Strange Matter project. It allowed MRS Education Outreach to create programming at MRS Spring and Fall Meetings (e.g., hands-on activities, demonstration stage presentations, special poster sessions). Individual MRS researchers and students, as well as MRS student chapters and MS\&E departments, still participate in the annual NISE NanoDays (www.nisenet.org/e).

The Strange Matter exhibit continues to educate people on materials science; help visitors understand how things are created, changed, and used; and allow participants to examine how these materials can make new amazing things. It inspires wonder in the world of modern materials and provides a glimpse into the future that no one could have predicted. 